\title{
Conservation Tillage Training for Georgia's County Agents
}

\author{
Gary L. Hawkins, Agricultural Pollution Prevention - Row Crops \\ University of Georgia, Bio and Ag Engineering, P.O. Box 748, Tifton, GA 31793-0748, \\ ghawkins@uga.edu
}

\section{R. Dewey Lee, Extension Agronomist - Feed Grains}

University of Georgia, Crop and Soil Sciences, PO Box 1209, RDC, Tifton, GA 31793, deweylee@uga.edu.

\section{Julia Gaskin, Land Application Specialist}

University of Georgia, Bio and Ag Engineering, 619 Driftmier Engineering Center, Athens, GA 30602, jgaskin@engr.uga.edu

\section{W. (Wayne) Reeves, Research Agronomist}

J. Phil Campbell Sr. Natural Resource Conservation Center - USDA-ARS, 1420 Experiment Station Road, Watkinsville, GA 30677, dwreeves@uga.edu.

\section{Koralalage S.U. Jayaratne, Evaluation Specialist}

College of Family and Consumer Sciences, UGA, 226 Hoke Smith Annex, Athens, GA 30602, sunil@uga.edu.

\section{Glendon H. Harris, Extension Agronomist - Environmental Soil and Fertilizer University of Georgia, Crop and Soil Sciences, PO Box 1209, RDC, Tifton, GA 31793, gharris@uga.edu.}

\section{Ronnie Barentine, County Extension Agent - Pulaski County Georgia \\ University of Georgia, CAES, Pulaski County, PO Box 240, Community Service Center, Lumpkin St., Hawkinsville, GA 31036, barentin@uga.edu.}

\section{Written for presentation at the}

\footnotetext{
The authors are solely responsible for the content of this technical presentation. The technical presentation does not necessarily reflect the official position of the American Society of Agricultural and Biological Engineers (ASABE), and its printing and distribution does not constitute an endorsement of views which may be expressed. Technical presentations are not subject to the formal peer review process by ASABE editorial committees; therefore, they are not to be presented as refereed publications. Citation of this work should state that it is from an ASABE meeting paper. EXAMPLE: Author's Last Name, Initials. 2006. Title of Presentation. ASABE Paper No. 06xxxx. St. Joseph, Mich.: ASABE. For information about securing permission to reprint or reproduce a technical presentation, please contact ASABE at rutter@asabe.org or 269-429-0300 (2950 Niles Road, St. Joseph, MI 49085-9659 USA).
} 


\title{
2006 ASABE Annual International Meeting Sponsored by ASABE \\ Portland Convention Center \\ Portland, Oregon \\ 9 - 12 July 2006
}

\begin{abstract}
Farmer interest in conservation tillage (CT) has increased with rising fuel prices, the new Conservation Security Program, and desire for improved resource stewardship. Research has shown that farmer's see maximum benefit to CT if it is part of a cropping system that includes cover crops and crop rotation. The CT system best suited for a particular operation will vary with the crop, site, soils, and other factors. Many county extension agents in Georgia indicated they needed further training to meet the informational needs of their farmers. Consequently, the University of Georgia College of Agricultural and Environmental Sciences created a multi-disciplinary conservation tillage educational task force to develop a training program. The College recognized the need for input from other agencies that had extensive experience in conservation and management of natural resources. The task force includes UGA-CAES faculty, USDA-NRCS personnel, USDA-ARS research scientists, and non-governmental representatives. A survey of the county agents was conducted to determine specific training needs and attitudes towards CT. The survey indicated most county agents had a positive attitude towards CT systems, but their knowledge was weak on the differences between CT systems and conventional systems in terms of: inputs, equipment, changes in soil quality and fertility, effects on yields and quality of different commodities, and specifics on how to implement CT practices. The survey also indicated that more information on the economics of CT systems was needed. Agents preferred a combination of classroom and field training. The results of the survey were used to develop specific training modules with the purpose of improving the knowledge level of county agents on conservation tillage systems.
\end{abstract}

Keywords. Conservation Tillage, Extension, Training,

(The ASABE disclaimer is on a footer on this page, and will show in Print Preview or Page Layout view.)

\footnotetext{
The authors are solely responsible for the content of this technical presentation. The technical presentation does not necessarily reflect the official position of the American Society of Agricultural and Biological Engineers (ASABE), and its printing and distribution does not constitute an endorsement of views which may be expressed. Technical presentations are not subject to the formal peer review process by ASABE editorial committees; therefore, they are not to be presented as refereed publications. Citation of this work should state that it is from an ASABE meeting paper. EXAMPLE: Author's Last Name, Initials. 2006. Title of Presentation. ASABE Paper No. 06xxxx. St. Joseph, Mich.: ASABE. For information about securing permission to reprint or reproduce a technical presentation, please contact ASABE at rutter@asabe.org or 269-429-0300 (2950 Niles Road, St. Joseph, MI 49085-9659 USA).
} 


\section{Introduction}

The term conservation tillage (CT) can be described and defined to include different tillage practices such as no-till, ridge-till, mulch-till, zone or strip-till, zero-till and reduced tillage (Titi, 2003; CTIC, 2004; GA-NRCS, 2002). Each of these types of CT are specifically defined based on the type of tillage and means and amount of residue remaining after planting. The CTIC (2004) and USDA-Natural Resource Conservation Service defines conservation tillage as a tillage method that leaves a minimum of $30 \%$ residue cover on the soil service after planting. Georgia has increased that to $50 \%$ residue remaining on the surface after planting for purposes of conserving soil moisture (GA-NRCS, 2002). The use of CT has multiple benefits for the farmer, the local community and the region where CT is adopted. Some of the benefits includes but are not limited to: improved water, soil and air quality, reduced erosion, as well as reduced labor and operating costs (CTIC, 2002). Conservation tillage adoption has increased from $26 \%$ in 1990 to $41 \%$ in 2004 on a national level (CTIC, 2006). In Georgia alone the adoption rate for CT has increased from $18 \%$ in 1990 to $34 \%$ in 2004 . As the adoption rate increases across Georgia, the Southeast and the nation, the local County Extension agent will continually get more and more questions related to conservation tillage management issues such as soil fertility, soil moisture, equipment set-up, soil biology, cover crops, and weed control.

The County Extension Agents in Georgia identified the need for more information on conservation tillage systems on the 2004 annual needs assessment. This needs assessment is compiled by the University of Georgia College of Agriculture and Environmental Sciences as a way to better develop programs and trainings for the agents. From the assessment, the Associate Dean for Extension charged a multi-agency, multi-departmental educational task force to develop training for mainly Agricultural and Natural Resource Agents. To meet the needs of the agents the educational task force developed a training with four objectives as follows: 1) Provide a consistent statewide Conservation Tillage Systems training for all County Extension Faculty; 2) Provide modules covering various topics that can be used by County Extension Faculty to educate their clients on conservation tillage; 3) Provide training to County Extension Faculty based on a needs based topic; and 4) Conduct Needs Assessment (Pretraining) and Post-Training Survey to determine knowledge, ability and confidence with conservation tillage topics.

\section{Needs Assessment:}

\section{General Demographics:}

To ensure that the CT educational task force was preparing a meaningful and useful training, a survey was developed and mailed to nearly 106 Agriculture and Natural Resources (A\&NR) agents with major responsibilities in commercial row crop agriculture. The survey was designed and administered to determine the agent's current knowledge, attitude and confidence about CT. There was a ninety percent $(90 \%)$ return rate for the surveys. The responses on the survey were analyzed via Administrative District (Figure 1) and for the state. 


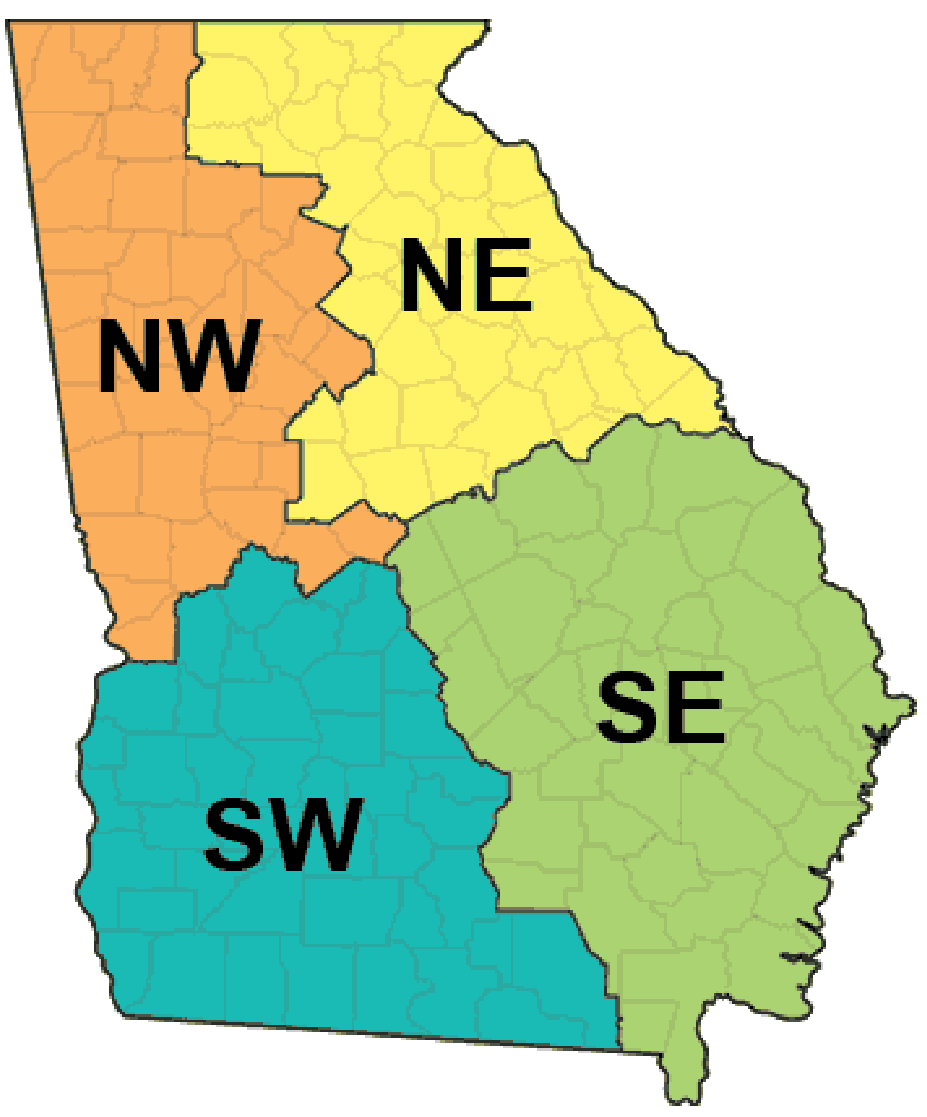

Figure 1. University of Georgia College of Agricultural and Environmental Sciences Extension District map. Copied from www.caes.uga.edu/extension/statewide.cfm

Seventy-two percent $(72 \%)$ of the agents stated that they have commercial row crops within their counties with $62 \%$ stated they spend most of their time with row crops. For clarification, a majority of row cropping counties are located in the coastal plain region of Georgia. Twentynine percent of the respondents stated that they often deliver CT programming. Thirty-nine percent of the agents in the southern regions often delivered CT training; however, $33 \%$ of the agents in the northern regions either occasionally or never offered CT training. These two percentages are related to the fact that there is more row crop agriculture in the southern regions verses the northern regions of Georgia.

The agents, as would be expected, have different levels of experiences within Extension with years of service ranging from 1 to 29 with an average of 17 years. More experienced agents delivered programming very often $(23.2 \%)$ and less experienced agents delivered programming occasionally (15.5\%) but the distribution was evenly spread across very often delivered to never delivered. Thirty-five percent of the respondents had bachelor's degrees and $64 \%$ had graduate degrees. 


\section{Knowledge, Attitudes and Confidence:}

Knowledge of CT was measured on the initial survey though the use of 25 questions. The questions tested the knowledge of the agents in the areas of: management inputs; soil fertility, quality and management; crop-specific or commodity management issues; how-to's; equipment requirements and operations; ecology; water conservation and management and economics. The mean score of correctly answered questions was $64 \%$ which indicated that training was needed to develop adequate knowledge of CT. A breakdown of question types indicated that improvement was needed in the areas of inputs, soils, commodities, how-to's, and equipment; consequently the training sections needed to be heavily weighted towards these topics. There was a strong correlation between knowledge and frequency of delivering CT programs. From a regional perspective, all regions had a similar knowledge of the topics covered with ranges of knowledge from $62 \%$ to $66 \%$.

Attitudes toward CT were measured using a 12-item survey with a 5-point Likert scale. The items were stated in a negative manner with the totals of each item summed for a final score. A total score of 12 would have indicated a very positive attitude with a 60 representing a very negative attitude. The mean attitude score was a 22.9 which indicates there is a positive attitude towards CT. Similar to the knowledge scores, there is a positive correlation between attitude and delivery of CT programs. A breakdown of scores indicated that there were only positive or very positive attitudes towards CT with no negative attitudes. However, the scores also indicated that there was a need to develop stronger positive attitudes towards CT.

Confidence levels in delivering programs on certain topics were satisfactory. However, they lacked confidence in delivering educational programs on topics such as state and federal CT assistance programs, cost-benefits, and how to use conservation tillage.

Based on the results of the knowledge, attitude and confidence questions on the survey, the training needs included economic analysis and cost-benefit data. The agents also desired the training should include both classroom and field training. Materials should be made available through printed and CD formats.

\section{Conservation Tillage Training:}

As stated earlier, the agents experience varies, their backgrounds vary and their knowledge of soil systems vary. The CT Educational Task Force designed two separate two-day workshops to provide basic as well as more advanced information on various aspects of CT. The trainings were conducted in the fall (December 2005) and the Spring (April 2006). The training topics were split so that fall and spring specific topics could be covered separately and as they would be occurring on farms. Prior to and after each training, agents were given tests to document the effectiveness of the training. A breakdown of each training session is given below.

\section{Fall Training}

The Fall training was conducted over two days to provide ample time to cover the topics as well as to provide opportunities for questions, interaction and discussion. The training was also conducted in three different sessions to provide smaller classes as well as providing the 
speakers with opportunities to change the presentations some to meet specific regional farming conditions of Georgia.

To honor the request of the agents to have both classroom and field training, the following topics were divided to provide both education opportunities. The topics with "(Field") were conducted in the field and the other topics were discussed in a classroom setting.

- Overview of conservation tillage systems

- Basic soils review

- Use, type, and management of cover crops

- Soil sampling, fertility, and quality (Field)

- Affect of planting date on various cover crops (Field)

- Equipment (Field)

- Tillage needs and timing

- Changes in input

- Economics

As can be seen in the list, the Fall training was designed to educate the agents on the preparation of the soil for the planting of cover crops to prepare the system for the planting the summer crop. Both the classroom and the field work sections of the training provided the agents with handouts and information that could be used to assist farmers in getting their land prepared for conversion to a CT system as well as providing agents with ideas and reasons for advancing the management of farms that have previously been using CT.

\section{Spring Training:}

Similar to the fall training, the Spring training was conducted over two days with classroom and field education opportunities. Topics covered in the Spring training consisted of:

- Cover crop termination

- Seedling disease issues

- Insect issues in all major crops

- Planting of summer cash crops

- Cover crops (Field)

○ Killing (chemical and mechanical)

- Biomass production

○ Equipment set-up

○ Soil pits

- Fertility issues

- Water relations

- Weed management 
- Pulling the CT SYSTEM together

As can be seen from these topics, the emphasis of the spring training was to educate the agents on the timing of killing the cover crop, potential biomass values, nutrient cycling and, carbon storage, management of pests, and how to provide for managing the summer cash crop in the system.

\section{Conclusion:}

The Georgia County Extension Agents recommended in their annual programming request that training on Conservation Tillage be developed. To ensure the training met the needs of the agents, as well as to determine their current knowledge, attitudes and confidence in CT, a survey was mailed to Agricultural and Natural Resource (A\&NR) agents with $90 \%$ of the surveys being returned. Based on survey analysis, agents needed training to develop adequate knowledge of CT. Their attitudes toward CT were positive, but their confidence in educating farmers on state and federal assistance programs, cost-benefits and how to implement CT was low.

Two separate two-day trainings were developed to cover fall and spring specific CT issues. Both trainings offered classroom and field education opportunities to provide information that could be transferred to farmers. The Fall training dealt specifically with topics on establishment and management of cover crops for winter cover. The Spring training dealt with the killing of the winter cover crop, preparation of the seed bed for summer crops, nutrient cycling and fertility management, and pest and water issues related to the summer crop. Overall the training provided a needed program as requested by Georgia County Extension agents to better their knowledge, attitude and confidence is educating farmers on conservation tillage.

\section{Acknowledgements}

The authors would like to thank the Georgia County Extension Agents for their participation in the Conservation Tillage training, the University of Georgia College of Agriculture and Environmental Sciences Administration for charging the group to develop this training and all of the speakers who were a part of the training. The authors would also like to thank Ms. Sarah Cates for printing and preparing the material notebooks that were distributed to all participates, Auburn University for their contribution of materials and Georgia P2AD for their participation.

\section{References}

CTIC. 2002. Tillage Type Definitions. Core 4, Conservation Tillage Informational Center. Available at http://www.ctic.purdue.edu/Core4/CT/Definitions.html. Accessed 1 May 2006.

CTIC. 2006. Crop Residue Management. Conservation Tillage Informational Center. Available at http://www.ctic.purdue.edu/CTIC/CRM.html. Accessed 20 April 2006. 
GA-NRCS. 2002. Residue Management, No-till/Strip Till (Acre), Code 329A. Natural Resource Conservation Service Conservation Practice Standard.

Titi, A.E. 2003. Soil Tillage in Agroecosystems. Boca Raton, FL,: CRC Press. 